ERRATUM

Christopher D. Elvidge $\cdot$ John B. Dietz

Ray Berkelmans · Serge Andréfouët

William Skirving · Alan E. Strong · Benjamin T. Tuttle

\title{
Satellite observation of Keppel Islands (Great Barrier Reef) 2002 coral bleaching using IKONOS data
}

Published online: 28 August 2004

(c) Springer-Verlag 2004

\section{Coral Reefs (2004) 23:123-132}

In the printed version of the article, Figures 3 and 4 have been printed in the the wrong color. The correct figures are as follows:

The online version of the original article can be found at http://dx.doi.org/10.1007/s00338-003-0364-8

C. D. Elvidge $(\varangle)$

NOAA National Geophysical Data Center,

325 Broadway, Boulder, CO 80305, USA

E-mail: chris.elvidge@noaa.gov

Tel.: + 1-303-4976121

J. B. Dietz

Cooperative Institute for Research in the Atmosphere,

Colorado State University, Fort Collins, CO 80523, USA

R. Berkelmans

Australian Institute of Marine Science

and the CRC Reef Research Center,

4810 Townsville, Queensland, Australia

S. Andréfouët

Institute for Marine Remote Sensing,

College of Marine Science, University of South Florida,

St. Petersburg, FL 33701, USA

W. Skirving

Cooperative Institute for Research in the Atmosphere,

Colorado State University (NOAA-NESDIS Office of Research and Applications), Camp Springs, MD 20746, USA

A. E. Strong

NOAA NESDIS Office of Research and Applications,

Camp Springs, MD 20746, USA

B. T. Tuttle

Cooperative Institute for Research in Environmental Sciences,

University of Colorado, Boulder, CO 80305, USA

Present address: S. Andréfouët

UR Coreus-Institut de Recherche pour la Développement (IRD), Nouvelle Calédonie
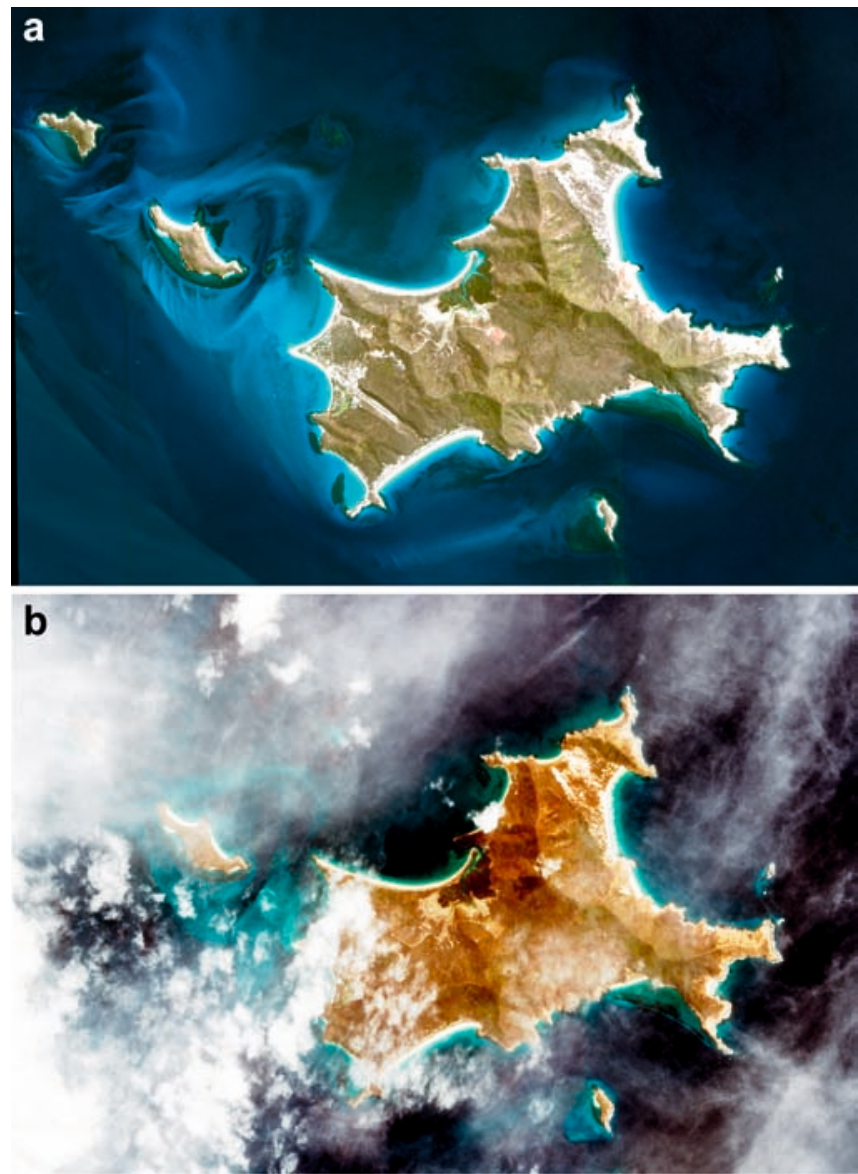

Fig. 3 August 22, 2001 (a) and April 15, 2002 (b) IKONOS images of the Keppel Islands. Bands 3, 2, 1 as RGB 


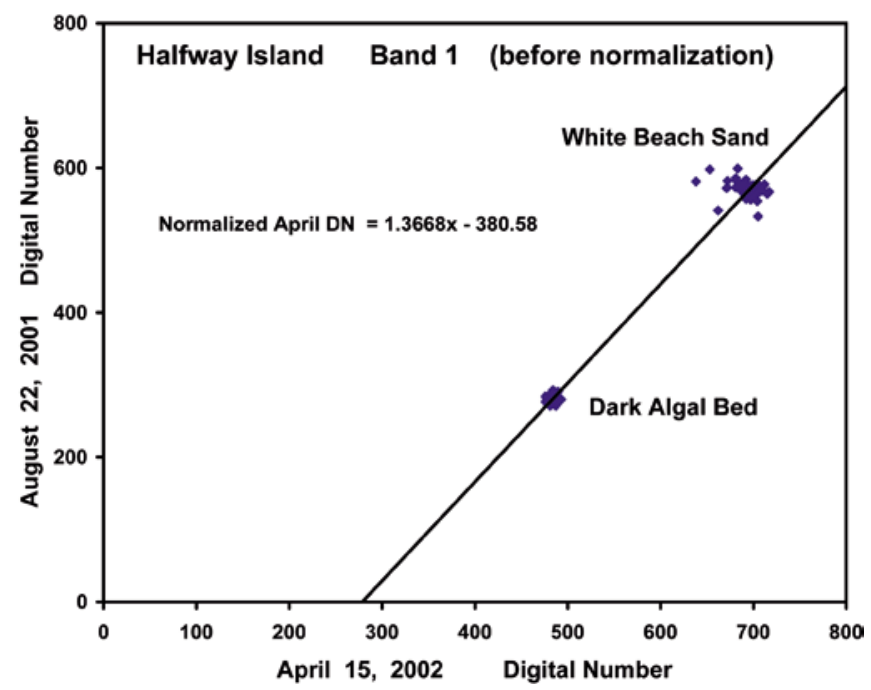

Fig. 4 Scattergram of the DN values for the dark algal bed and white beach sand pixel sets used as pseudo-invariant features for the Halfway Island study site. Overlaying the pixel data is the regression line 